\title{
НАСЕЛЕНИЕ РОССИИ В ЗЕРКАЛЕ ПЕРЕПИСИ 2010 ГОДА
}

\section{АЛЕКСАНДР АКИМОВ}

Начиная с 1993 г., практически одна и та же группа исследователей, сейчас работающих в Институте демографии Научно-исследовательского университета «Высшая школа экономики», а до 2007 г. представлявших Центр демографии и экологии человека Института народнохозяйственного прогнозирования РАН, публикует ежегодные демографические доклады под названием «Население России». Последний из них, восемнадцатый-девятнадцатый по счету, увидел свет в $2013 \Gamma^{1}$. Двойной номер отражает специфику этого выпуска доклада - он содержит анализ результатов Всероссийской переписи населения 2010 г., и чтобы отразить ситуацию 2010 г. уже с учетом результатов переписи, авторам пришлось ждать окончания их разработки органами статистики.

Рецензируемое издание, по сути дела, представляет собой комбинацию результатов двух исследовательских работ: анализа результатов переписи населения России 2010 г. и мониторинга демографической ситуации, проводимого его авторами вот уже более 20 лет. Безупречный научный аппарат (ссылки на источники, пояснения и сноски) наряду с графической наглядностью (много графиков и таблиц) делают доклад полезным и доступным источником данных для самых разных категорий читателей от профессионаловдемографов и лиц, принимающих решения, до студентов недемографических специальностей и широкой общественности.

Представленные таблицы и графики, сопровождаемые детальными комментариями профессионалов относительно способа получения информации и выводами по результату анализа статистических данных, дают читателям - представителям смежных исследовательских областей, студентам, да и людям, далеким от статистики и демографии, - пример того, как демографы получают свои научные результаты. Это важно в педагогическом отношении для студентов и в просветительском - для широкой общественности, озабоченной демографической ситуацией в стране.

\footnotetext{
АЛЕКСАНДР ВЛАДИМИРОВИЧ АКИМОВ. ИНСТИТУТ СТРАН ВОСТОКА. РОССИЯ. E-mail: akimov@ivran.ru СТАТЬЯ ПОСТУПИЛА В РЕДАКЦИЮ В ДЕКАБРЕ 2013 Г.
}

1 Население России 2010-2011. Восемнадцатый-девятнадцатый ежегодный демографический доклад Института демографии НИУ «Высшая школа экономики». Ответственный редактор А.Г. Вишневский, Издательский дом НИУ ВШЭ, Москва, 2013, 530 страниц. Полный текст доклада можно найти по адресу http://demoscope.ru/weekly/knigi/ns_r10_11/akrobat/nr10_11.pdf. 
Данные максимально актуализированы - есть даже оценки на 2013 г. Включение в доклад, посвященный населению России, международных сопоставлений позволяет ясно видеть демографическое положение России на мировом фоне. Результаты исследования полезны отнюдь не только для демографов, но и для экономистов (например, анализ демографической нагрузки), экономгеографов (различие демографических показателей и демографических тенденций по субъектам федерации), социологов (семейная структура), политологов (численность народов) и т.д. На базе данных переписи населения авторами проведено глубокое исследование этнических процессов на территории России. При этом не утрачивается демографическая специфика исследования, скажем, методы демографического анализа применяются для исследования возрастного состава основных народов России. Включение в чисто демографические сюжеты значительного по объему материала по экономическим и этнологическим вопросам обогащает анализ, доклад явно выходит за рамки «чистой» демографии и является междисциплинарным исследованием народонаселения России.

Подробное описание статистических категорий и описание реальных трудностей опроса населения при переписи, как это сделано, например, в разделе об источниках доходов населения, делает доклад, в том числе, и полезным учебным пособием для студентов и аспирантов самых разных экономических и социологических специализаций.

При том, что доклад написан большим авторским коллективом, разделы однородны по стилю как с точки зрения подачи статистического материала, так и по характеру текста, что облегчает чтение. Авторам удалось совместить скрупулезный статистический анализ с публицистической подачей материала. Большим преимуществом доклада является обобщение основных результатов анализа в Заключении с публицистической формулировкой основных выводов. Это делает результаты доклада ясными для неспециалистов.

В докладе представлены конкретный статистический анализ и экспертные оценки авторов по наиболее принципиальным вопросам демографического развития страны состоянию и перспективам рождаемости и смертности. В седьмом разделе дана оценка проводимой в стране демографической политики по повышению уровня рождаемости. При анализе статистических данных результат выглядит достаточно оптимистично, поскольку текущие результаты политики по стимулированию рождаемости дают определенный подъем числа рождений, но перспективы роста коэффициента суммарной рождаемости оценены очень осторожно. Авторы прогноза считают, что к 2030 г. этот показатель составит 
примерно 1,7, то есть будет ниже, чем принято в Концепции демографической политики в Российской Федерации.

Эта оценка выглядит убедительной, поскольку она совпадает с трендами, сложившимися во многих развитых в экономическом отношении странах. Да, есть развитые страны, где этот показатель выше, но этот факт не свидетельствует в пользу того, что Россия может быстро добиться изменений в этой области на приемлемых для общества и государства условиях. Коэффициент суммарной рождаемости можно быстро повысить, изменив миграционную политику и допустив переселение в Россию семей из Центральной Азии.

Инерционность демографических процессов хорошо иллюстрирует восьмой раздел, посвященный смертности и продолжительности жизни. Проблема высокой смертности мужчин в России стоит уже многие десятилетия, но, несмотря на то, что определенные меры для ее решения принимаются, изменения к лучшему незначительны.

Очевидно, что меры по снижению заболеваемости и смертности в стране потребуют больших инвестиций и высоких уровней бюджетных расходов в течение долгого времени. В этом смысле конкуренция между мерами по снижению смертности и повышению рождаемости будет продолжаться. Демографический анализ определенным образом указывает на методы социально-экономической политики, которые должны быть предприняты для улучшения демографической ситуации. Никакая долгосрочная политика, никакие экономические планы не могут игнорировать демографическую реальность.

Сдвоенный доклад содержит много данных, характеризующих процессы, которые предопределяют судьбу страны на многие годы вперед и дают возможность оценить предлагаемые программы или направления развития России. Динамика численности населения, его состав, доходы, состояние домохозяйств в значительной степени определяют количество и структуру потребителей и производителей, то есть людей как субъектов экономической деятельности.

Данные об источниках средств к существованию показывают страну с высокой занятостью населения, в которой значительная часть населения зависит от государственных пособий и пенсий, но еще около 10\% населения опираются на натуральное хозяйство личные подсобные хозяйства. Сложившаяся структура доходов ведет свое существование со времен СССР, два десятилетия реформ не привели к ее коренной ломке. Формы доходов, связанные с новой, основанной на частной собственности на средства производства, системой хозяйства, - сбережения и сдача в аренду имущества - распространены очень мало. 
Трудно однозначно утверждать, хороша или плоха такая малая изменчивость структуры источников средств к существованию. Кроме того, основной их источник трудовая деятельность - может означать работу в собственном бизнесе. Но очевидно, что роль государства в обеспечении населения средствами существования очень велика. Это сужает возможности для изменения структуры расходов государственного бюджета, отсекая варианты экономической модернизации, построенные на значительных государственных инвестициях в экономику.

Вместе с тем, коль скоро речь идет о результатах переписи населения, можно упрекнуть ее организаторов в том, что в программе переписи слабо представлены показатели, характеризующие изменения в российском обществе, связанные с новыми экономическими отношениями, сложившимися после 1991 г. Впрочем, можно предположить, что в нашей стране вопросы об экономическом положении опрашиваемых могут остаться без ответа или ответ будет искажен.

Важной составляющей инвестиционного климата в России остается невысокая мобильность населения. Как подчеркивается в девятом разделе доклада, за пределами своего региона проживания работают только 2 млн человек или менее $3 \%$ занятых. Этот факт может указывать на то, что уровень жизни в регионах фактически не так уж низок, чтобы люди были готовы ехать куда угодно, лишь бы получить работу, как это происходит в государствах Центральной Азии, но, с точки зрения инвесторов, в случае крупного проекта, требующего привлечения большого числа работников, это минус.

Вторая важная особенность миграционных процессов в России - дрейф населения на запад - также развеивает многие иллюзии относительно стратегии развития страны и ее регионов. Перемещение населения из Сибири и с Дальнего Востока на запад страны идет уже не одно десятилетие, но долгосрочной стратегии по перелому этого тренда или хотя бы рациональному приспособлению к нему пока нет. Тот факт, что Москва и Московская область, а также Санкт-Петербург и Ленинградская область долгое время остаются основными регионами притяжения населения, свидетельствует о структуре рынка труда в стране, которая создает большой спрос в указанных центрах, но приводит к вымыванию рабочей силы из других регионов.

В том же разделе отмечен важный факт. В сельской местности России стабилизатором численности населения в 1990-е годы стала иммиграция из стран СНГ. Если иммигранты из этих стран в городах заметны и вопрос об их пребывании волнует общественное мнение, то сельские жители из стран СНГ в России представляют собой явление, которое не до конца осознано как в социальном и политическом, так и в 
экономическом плане. В сельской местности процесс может привести к тому, что образуются общины, говорящие на языках страны происхождения, выключенные из социально-политической жизни региона. С экономической же точки зрения, иммигранты в сельской местности потенциально являются рабочей силой, способной вывести сельскую местность из застоя.

В докладе анализируется и такой существенный компонент современных демографических процессов в России, как внешняя миграция. В соответствующем разделе много внимания посвящено учету мигрантов. Данные переписи и текущего учета сильно различаются, что делает многие оценки неопределенными. Безусловно, разнобой в оценках статистических органов отрицательно сказывается на анализе внешних миграций, а это очень политизированная область. В этой связи экспертные оценки имеют большое значение. Они занимают значимое место в тексте раздела.

Представленный в докладе материал дает подробную картину демографических процессов в России, которая может представлять интерес для зарубежного читателя. Возможно, было бы полезно издать доклад на английском языке. Содержащийся в нем глубокий анализ российской переписи населения может заинтересовать зарубежных демографов, которые не имеют возможности оценить результаты переписи непосредственно. Кроме того, ценные сведения для оценки перспектив развития бизнеса в нашей стране могли бы найти в книге иностранные инвесторы, желающие работать в России.

Надеюсь, мысли и ассоциации, отраженные в этой краткой рецензии, показывают, сколь многообразны сюжеты, затронутые в докладе, каковы многочисленные связи демографических процессов и проблем, отраженных в нем, с другими очень важными для нашей страны проблемами, связанными с долгосрочной стратегией развития, да и с текущими социально-экономическими вопросами, требующими реакции общественности и решений от властей разного уровня. 